\title{
THE EFFECTS OF PROLONGED ECONOMIC STRESSORS IN MINORITY LOW-INCOME NEIGHBORHOODS ON FAMILY FUNCTIONING AND CHILD DEVELOPMENTAL OUTCOMES
}

\author{
Peter Kamps
}

Chicago Department of Family and Support Services, USA

\begin{abstract}
Poverty and prolonged periods of unemployment have been shown to affect the ability of families to function as evidenced by effective parental interaction and child developmental outcomes. Minority families, particularly African-Americans and Latinos, are more likely to live in urban neighborhoods characterized by concentrated poverty, than Caucasians. This paper explores the inter-relationship between federal welfare policy, institutional barriers such as housing discrimination, as well as banking practices, on family stability in minority low income neighborhoods. The unintended consequences of neighborhood segregation on family functioning and child developmental outcomes, neighborhood violence, and barriers to upward mobility to more stable neighborhoods are examined. Three models which explore the dynamics of economic stressors within the family unit, the impact on cognitive and psychological development of the child and the role of effective parental/child interactive strategies in light of profound economic hardship are presented. Finally, this paper covers research on the underlying dynamics of concentrated urban poverty on marital/family stability and recommends policies to promote family resiliency.
\end{abstract}

Keywords: poverty, policy; family, hardship

\section{Introduction}

Demographic and external economic factors have hindered the migration of urbanized low income minority families and children from neighborhoods characterized by high poverty into more stable neighborhoods within the United States over the past several decades. Despite the economic recovery since the Great Recession of 2008, African-Americans and other minorities continue to be disproportionately represented in the ranks of the unemployed and the poor.

Since 2008, overall unemployment declined slightly from $6.4 \%$ within the U.S. to $6,3 \%$ in 2015 . Within the African-American community, unemployment during the same period remained much higher at approximately $11 \%$ Structural factors such as a decline in high-wage manufacturing jobs, stagnation in real wages, slow economic growth, all have contributed to this decline. Within the City of Chicago, African-American unemployment was $18.7 \%$, compared to $5.1 \%$ within the Caucasian population during 2015. Prolonged unemployment within a family increases the probability a child will be living in poverty.

\section{Adult and Child Poverty}

Poverty rates within the African-American and Latino population are significantly greater than within the Caucasian population. The U.S. overall poverty rate stood at $14.7 \%$ while poverty rates were $22.6 \%$ in the Hispanic community and $25.4 \%$ in the African-American community during 2015. Although these racial/ethnic groups reported a decrease in poverty from 2014, they still remained significantly higher than the overall percentage of poor individuals. Within the City of Chicago, poverty rates are also disproportionately concentrated in the African-American and Latino populations. According to the 2015 ACS 1 year estimates from the Census Bureau, the overall poverty rate in Chicago stood at 20.9\%, 31.5\% for African-Americans, $21.8 \%$ for Latinos, and only $13.9 \%$ for Caucasians. Poverty within the African American Community was 
$26.2 \%$ in Los Angeles. Among the Latino population, poverty stood at $21.8 \%$. In comparison, Caucasians who were residing in Los Angeles reported a poverty rate of only 17.4\%. Within the United States, poverty is dis proportionally concentrated among the youth population or $20.7 \%$ of all children under 18 years of age. Institutional barriers such as low wages and discrimination have also resulted increased the likelihood that low income families will continue to live in neighborhoods characterized by high poverty rates, away from the suburbs and non-metropolitan areas where entry level job growth is likely to be higher.

Nationwide, rates of poverty for African-American children and children of Latino decent (0-17 years of age) are much higher than their Caucasian counterparts. During 2015, 40.3\% of African American children 0-5 years of age were below the poverty level within the US. For 6-17 year olds this percentage decreased to $34.7 \%$. The poverty rate for Caucasian children 0-5 years of age was $18.5 \%$ for $6-17$ year olds this percentage was $15.8 \%$. For Hispanic children zero to seventeen years of age, the poverty rate stood at $30.5 \%$. Several significant federal policy initiatives have played a major role in reducing the opportunities of low income families to move into more middle-class neighborhoods by constraining the ability of low income families to improve their economic situation. In addition, states have varied in their practices in making Temporary Assistance to Needy Families (TANF) accessible to those who qualify.

The passage of the Personal Responsibility and Work Opportunity Reconciliation Act of 1996 (PWORA) has had a significant impact on how minority families cope with prolonged economic hardship. The signature outcome of this legislation was a 5 year (60 month) lifetime time limit for low income families to obtain federal assistance through TANF as well as cash assistance, potentially increasing the duration of time a family remains in poverty. Since the passage of the PWORA Act in 1996, states have had more autonomy to modify the primary "safety net" for families. This has included reducing the number of months a family may be eligible for benefits and the implementation of increasingly restrictive eligibility requirements for programs such as food stamps, making them more inaccessible.

Work requirements, with the threat of losing income assistance were also instituted. Leonard and Mas in their 2008 study of infant and maternal health within states which reduced the lifetime TANF benefits timeline found a dramatic increase in infant mortality. External economic factors such as employment barriers and federal legislation such as The PWORA Act have made it more likely low income minority families will remain in segregated neighborhoods characterized by high poverty concentrations. Unequal banking practices also make it more difficult for low income residents to move into more stable neighborhoods.

\section{Discriminatory Banking Practices}

A 2013 Study of mortgage practices by the Woodstock Institute in Chicago found that women were more likely to be denied mortgages than their male counterparts. Female mortgage applicants were on average less likely to have home purchase mortgage originated than males by $8 \%$. In addition, females were $21 \%$ more likely to have their home refinance requests denied. Significantly, the study found female headed joint applications were much less likely to be originated than male-headed joint applications. The greatest disparity occurred for AfricanAmerican female headed households who were 34\% more likely to have their mortgage applications denied than their male headed African-American households. The mortgage disparity was even greater for AfricanAmerican females seeking to refinance, with these households $44 \%$ less likely to receive re-finance home origination loans. Latino female-headed households were 19 and 29 percent less likely to have mortgage and refinance origination home loans completed than their male headed Latino counterparts.

\section{Neighborhood Segregation}

Massey (1988) in his study "The Dimensions of Residential Segregation" defines this neighborhood construct according to five measures-evenness, exposure, concentration, centralization and clustering. At the higher level, 
neighborhood segregation is defined by Massey and others as "the degree to which two or more groups live, separately, from one another, in different parts of the urban environment."

1) Evenness - The differential distribution of social groups among area units in a city. Segregation is said to occur when a minority group is unevenly distributed over area units.

2) Exposure - Exposure refers to the degree of potential contact, or the possibility of interaction between minority and majority group members within the city. Exposure attempts to measure the experience of segregation as felt by the average minority or majority member.

3) Concentration - Refers to the relative amount of physical space occupied by a minority group in the urban environment. Groups that occupy a small share of the total area in a city are said to be residentially concentrated

4) Centralization - Centralization refers to the degree to which a group is spatially located near the center of an urban area. In the 1970's urban central areas were characterized by a high concentration of minorities since this was usually associated with sub-standard housing.

5) Clustering - The degree to which area units inhabited by minority members adjoin one another.

A high degree of clustering implies a residential structure where minority areas are contiguous and closely packed, creating a single large ethnic or racial enclave.

Chicago, New York and Los Angeles County (which includes the City of Los Angeles) all reported increases in the number of African-Americans living in high poverty neighborhoods between 2012 and 2014 (defined as $40 \%$ or more of neighborhood residents living below the federal poverty level). Within the City of Chicago, 145,000 low income African-Americans in Chicago during 2012 were living in neighborhoods where forty percent or more of the residents were below poverty. By the end of 2014, more than 50\% of all Chicago African-Americans living in poverty were living in neighborhoods with high poverty concentrations. A similar pattern is evident in Los Angeles County. Of the 180,000 African-American residents below poverty, 66,000 lived in neighborhoods characterized by a high concentration of poverty during 2012. By 2014, close to 79,000 lived in neighborhoods where $40 \%$ or more of neighborhood residents were below poverty, an increase of $20 \%$. (Table 1) 
Table 1-Demographic Change in African-Americans Living Below the Poverty Level and In Neighborhoods Where 40\% or More are Below the Poverty Level: New York, Chicago and Los Angeles

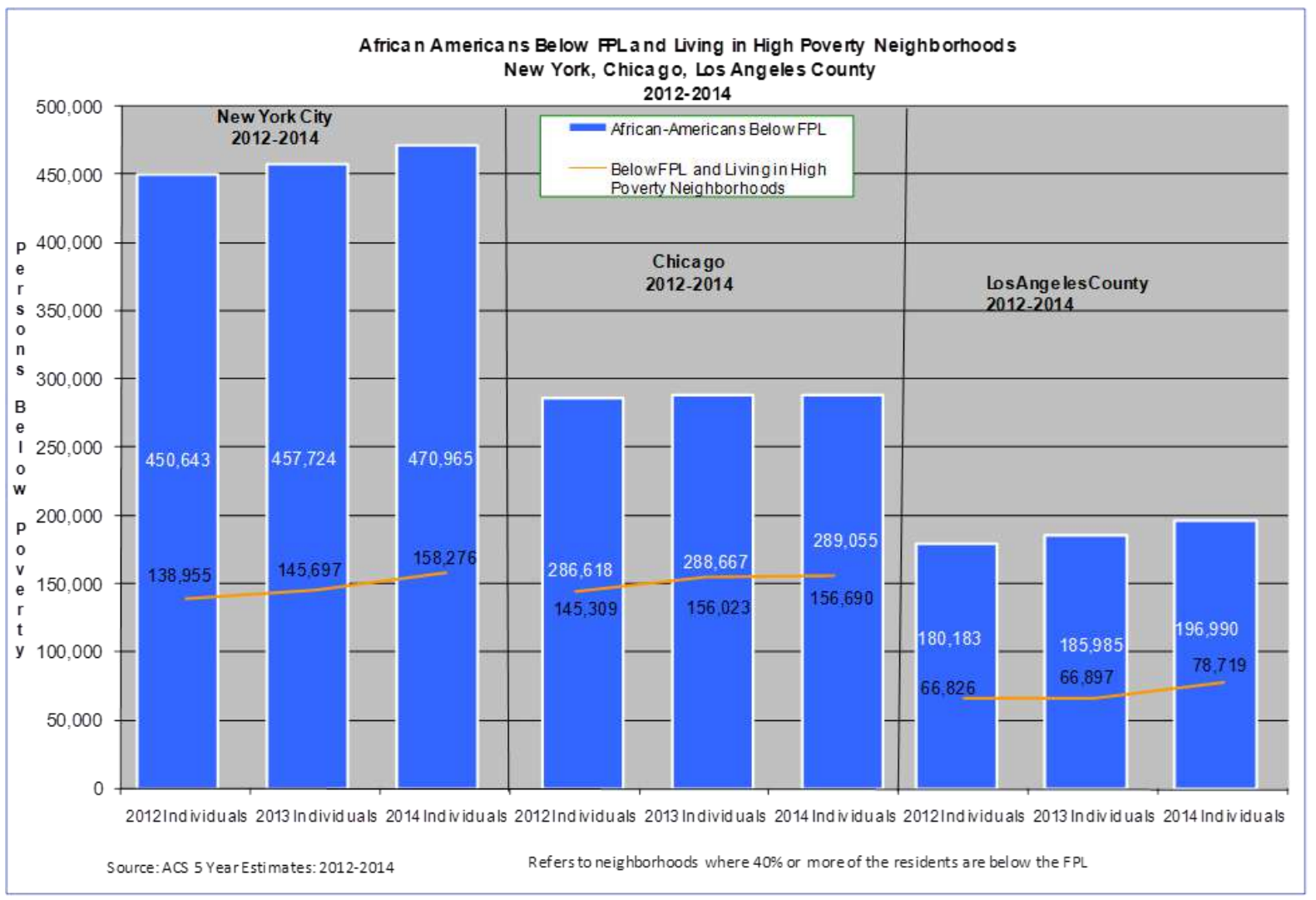

Low income African-American families and other minority sub-populations are more likely to experience social isolation due to residency in neighborhoods characterized by high concentrations of poverty and thereby have fewer community resources at their disposal. This can have profound implications for the stability of the family unit, and the overall developmental outcomes of children. Residency in a single female headed households also increases the probability a child will be living in poverty. The percentage of single female headed families with children below the FPL has increased from $37.4 \%$ of all female headed households with children in the United States during 2010 to $39.2 \%$ in 2015 . External economic forces (i.e. prolonged periods of exposure to poverty or other forms of economic hardship), as well as neighborhood conditions (disparities in access to medical care) strongly impacts family dynamics. However, parental strategies can mitigate against these forces, alleviating the psychological impact of hardship on children within the family unit. Family functioning, insofar as verbal interactions between mother and child, parental expectations for their child's achievement, cognitive stimulation in the child's home environment, was found to account to one-third to one-half of the disadvantages in verbal, reading and math skills for persistently poor children (Korenman, et.al: 1995).

Similar interrelationships have been established between poverty, prematurity, prenatal exposure to alcohol and illegal drugs, and behavioral problems (McLoyd et. al. 1996). Low SES is also a risk factor for chronic delinquency and early onset of anti-social behaviors and has been linked to family discord and parental mental illness (Yoskikawa, 1994).

Low income mothers face significant challenges when raising children in low income, poverty stricken neighborhoods. Robert Ceballo and Vonnie McLloyd, in a 2002 study of low income neighborhoods, assessed how neighborhood stressors such as high crime and poverty, affected parental strategies and informal social support networks Children who are living in these neighborhoods, characterized by concentrations of high poverty, are more likely to experience mental health problems, increased substance abuse usage, and exposure 
to crime. In addition their parents, fearful of safety, may be less likely to interact with neighborhoods and seek out neighborhood social supports, leading to social isolation, depression and low-self-esteem. Neighborhood social supports are critical in mitigating the stressors associated with long term economic hardship. Femaleheaded households are more likely to be characterized by low wages, low educational attainment, and minimal child support from fathers. Federal and state policies currently provide little support to facilitate improvement in the economic circumstances of these families.

\section{Family Functioning and Models of Parental Interaction/Child Development in Low Income Families}

Lower levels of income, educational attainment and occupational status have been associated with greater marital instability and less marital happiness. Three models have been extensively researched to account for the relationship of poverty to individual and familial dysfunction-the Family Stress Model, Family Investment Model and the Interactionist Model. These models examine the inter-relationship between socio-economic status and impaired family functioning, ultimately directing child developmental outcomes.

\section{Family Stress Model}

The Family Stress Model (FSM), first developed by Conger et. al. in 1994, asserts economic distress experienced by low-income parents serves as a significant contributor to marital discord, ultimately diminishing effective interaction with children. This interaction includes poor parenting practices (e.g. hostility, aggressive parenting techniques, and lack of warmth towards children). The FSM ascribes family economic stress to a greater likelihood of dysfunctional parental strategies such as coercion and putative parenting practices. Thus a direct inter-relationship is forged between familial pressures associated with economic hardship (i.e., poverty, loss of job, low wages) with emotional distress for both partners within the relationship. This, in turn, has a direct effect on the quality of parental interactions as well as parenting behaviors. This evidence has been corroborated by Vonnie McLoyd (2005) and other researchers who have demonstrated the interaction between economic stressors as indicated by low income status, prolonged poverty, economic hardship and parental conflict. Of particular concern is the impact of prolonged poverty on children, with increased risk of insecure attachments in relationships, negative behaviors such as acting out and aggression, and higher incidence of stress. Extreme poverty and prolonged episodes of poverty may exert more direct influences on the family than shortened periods of poverty. Prolonged exposure to economic stressors within the family unit, will adversely affect the child's overall cognitive, academic and emotional development. Internalization (low self-esteem, depression) and externalization of these behaviors (aggression, anti-social behaviors) are some of the negative child outcomes associated with prolonged exposure to economic hardship.

Simons (2016) et. al. found a significant correlation between prolonged periods of economic distress in family units and adolescent behavioral problems. In their study of 400 African-American families, the authors found that prolonged exposure to family economic distress was more likely to lead to dysfunctional adolescent behaviors resulting in a higher probability of delinquent behaviors, lowered educational achievements, and highrisk health behaviors, thus resulting in poor lifetime outcomes. Such negative adolescent behaviors also result in high costs for society, including higher probabilities of incarceration and medical emergency room visits. Therefore it is critical to examine the pathways through which economic distress impacts the development of adolescents and identify specific points of intervention which can alleviate the negative effects of family poverty, including income support, workforce services, and after-school programming. In summary, the Family Stress Model argues that parents undergoing periods of economic distress are more likely to experience depression, thereby leading to ineffective parenting techniques, and ultimately leading to behavior problems manifested within their children. Conversely, improvements in the economic circumstances of the family unit may have beneficial impacts on developmental outcomes for children and adolescents. Young children and adolescents are strongly influenced by the neighborhood environment in which they are raised. The availability and quality of key neighborhood institutions such as schools, child care, and health care resources can play a 
significant role in child or adolescent's development, well into adulthood. Housing quality and neighborhood diversity can similarly play a significant role in a child's later development. This is discussed below in the Family Investment Model theory of child development.

\section{Family Investment Model}

The Family Investment Model asserts that parents with higher socio-economic status are more likely to have the capacity to provide more resources for their children, such as better schools, access to educational resources and, by virtue of living in higher income community, access to better neighborhood resources such as parks and recreational facilities. Low income families, in comparison, must focus on the immediate needs of the family (e.g. food, housing), and thereby are unable to invest in the education and well-being of their children. The investment model of family functioning implicitly views family economic circumstances and functioning in terms of investment in the child's overall development. Predicated on the assumption that more socioeconomically affluent families are able to augment existing resources such as educational materials with advanced tutoring and investment in other activities such as specialized training, the model attributes a child's developmental outcomes to parental practices. Family resources therefore lead to child's academic success and overall development.

Social determinants such as adequate food, shelter, and medical care are investments the family makes, improving the probabilities of positive life outcomes of children well into adulthood. The investment model also postulates that lower income families must invest in immediate family needs and are continually vulnerable to an economic "tipping point". Poor families often do not have access to community resources such as quality health and child care, although this has improved somewhat since the implementation of the Affordable Care Act.

Bradley et. al. (2002) found that economic resources within the family unit were associated with positive parental investment in their child's cognitive and emotional growth, such as spending time with them doing homework and school projects. Critical to the child's development is their access to community resources such as peer networks, improved educational institutions, and other community neighborhood amenities such as parks.

\section{The Interaction Model}

The Interactionist model assumes that processes of social causation (external socioeconomic and demographic factors and social selection (those characteristics inherited between parent and child) are the most holistic and promising approach for predicting family dynamics and later childhood outcomes. The model predicts that both individual child and parental characteristics such as resiliency, persistence, high sociability, and a good work ethic in the face of adverse circumstances, as well as economic circumstances of the family unit, directly influence the stability of the family unit and child developmental outcomes. The model, postulates that parental warmth and support during a child's adolescence as well as socioeconomic status of the parent both play pivotal roles in the family's ability to function. Ultimately it is this interplay which determines the psychosocial adjustment of the child into early adulthood. In summary, initial personality characteristics prior to adulthood predict SES and family processes during the adult years. These, in turn, are handed over inter-generationally, predicting the social adjustment of subsequent generations of children.

Several other studies have corroborated these inter-relationships between economic hardship, parent emotional distress and parental conflicts, disruptions in effective parenting behaviors, and child behavioral problems. High levels of social support are critical in mediating the effects of prolonged poverty and may promote more sensitive parenting practices, particularly when such support cannot be purchased by these families and are often times out of reach. Negative parenting, defined as harsh discipline, coercive or non-responsive behaviors towards children, is more likely to lead to less positive child cognitive and developmental outcomes. Multi- 
generational networks may serve as a buffer in mitigating the effects of prolonged poverty by providing needed social supports to the immediate family unit. In addition, the quality of the parent(s) social support network and relationships beyond the mother -child relationship is critical in mitigating the effects of prolonged poverty on child developmental outcomes. Brooks-Dunn et. al. (2002) in their analysis of the Investment Model and Family Stress Model found that family stress processes were better predictors of behavioral problems and parental investments were better predictors of cognitive development.

\section{Parental Functioning}

Many low income parents face profound and difficult parenting responsibilities, leading to more harmful and confrontational parenting strategies. Conversely, parental warmth and moderate control have been associated with improved child development outcomes. Both parental warmth and authoritative parenting have been associated with higher levels of child well-being and are important components in the child's overall development. Isolation from support networks and neighborhood resources at the extreme end of the continuum is associated with child abuse and neglect. Residency in poor neighborhoods is associated with social isolation and mainstream jobs, resulting in limited resources available to the family unit in times of crisis.

\section{Poverty and Child Development Outcomes}

The internalization of problems and their externalization in terms of anti-social behaviors become more frequent the longer a child is in poverty. Thus, the external financial resources of families and the length of time families face economic hardship is correlated with poor child developmental outcomes

Externalization of problems through the expression of anti-social behaviors is similarly correlated with the length of time a family is in poverty In addition, a 1994 study found that having more low income neighbors predicted higher levels of anti-social behaviors among five year old (temper tantrums, destruction of objects) The underlying theory is that parents within low-income neighborhoods are less likely to reduce aggressive behaviors since this is seen as a primary means whereby their children can defend themselves. Neighborhood crime, feelings of insecurity and lack of safety, the interaction of peer group influences and poorer quality school environments may exacerbate this effect. Prolonged poverty may also affect the emotional functioning and parental behaviors within the family unit. McLeod et. al. (2007) found higher levels of irritability, depression, dysphagia and putative behaviors toward children for those families within the low SES spectrum, thus similarly leading to poor child developmental outcomes. Low-income adults are more likely to suffer from mental health problems and encounter more frequent adverse life events and chronic conditions ultimately leading to more putative and inconsistent parenting behaviors, and thereby leading to more sociology-emotional problems in children.

Adverse life events can also take a significant toll on the mental health of a child. In addition, factors such as overcrowded housing, prolonged exposure to poverty, and chronic family songstress (ire., parental conflict, depression, are likely to contribute within children to a lowered sense of self-worth. Children living in low income neighborhoods may also be routinely exposed to violence, Street violence is more likely to be present in low income neighborhoods and adolescents may become victims and witnesses to these crimes, resulting in post-traumatic stress disorder and more aggressive behaviors. Such isolation in low income communities is often due to neighborhood segregation. High-density segregation can also have a significant impact on a child's well-being, isolating them from diverse cultures and backgrounds. This is critical in the development of social skills needed later in adulthood. Racial segregation can also add to the stress of adolescents, as they are more likely to perceive community violence and crime in their neighborhoods. Low income African-American children and adolescents are more likely to live in neighborhoods of concentrated poverty (Duncan and Rogers, 1988) and Jargon (1994). Within Los Angeles County, the percentage of adolescents 12-17 in households below the FPL and living in high poverty neighborhoods (40\% or more of neighborhood residents) increased by $4 \%$ between 2012-2014 Within the City of Chicago, the increase was substantially higher with the percentage of 
adolescents 12-17 living in high poverty neighborhoods increasing by $18 \%$ during the same time period. (Table 2)

Table 2- Demographic Change in African-American Adolescents Living Below the Poverty Level and In Neighborhoods Where 40\% or More of Adolescents are Below the Poverty Level: New York, Chicago and Los Angeles

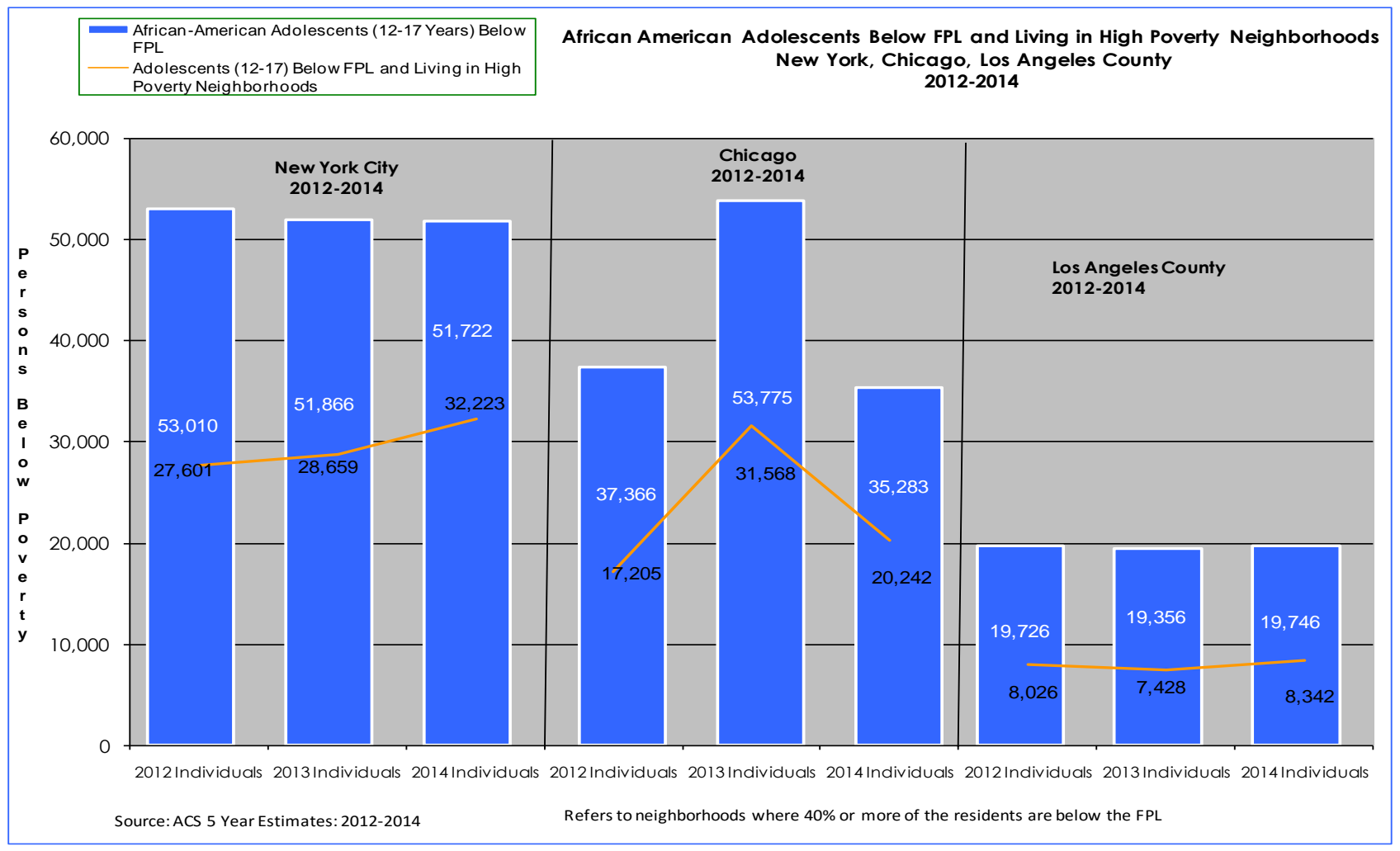

\section{Neighborhood Conditions-Child and Family Outcomes}

The socioeconomic mix of neighborhoods is positively correlated with levels of academic achievement within the young and adolescent population. Adolescents who grow up in high sociology-economic neighborhoods are more likely to complete high school as compared to their counterparts who grow up in low sociology-economic neighborhoods. Positive adult role models as well as the percentage of affluent neighbors have strong predictive power in terms of academic success. This supports the hypothesis of positive socialization and neighborhoods directly influencing child developmental outcomes In addition, more affluent neighborhoods are more likely to have quality health care, schools, parks, and other resources which can promote a child's development.

An increase in perceived safety, a decrease in the exposure to violence among parents, as well as an improved sense of well-being within families who have moved from poor neighborhoods (defined as census tracts with poverty rates higher than $40 \%$ ) to more affluent ones has been linked with an overall improvement in adult mental health as well as a decrease in juvenile delinquency.

Leventhal (2003) in an analysis of the effects of housing and neighborhoods on parental stresses and parenting strategies, conducted an analysis of the Moving to Opportunity Program in New York City. A housing relocation program which was implemented by HUD was also replicated in Baltimore, Boston, Chicago, and Los Angeles. The study was designed to assess the impact of familial movement from high-rise public housing in large urban areas to either private housing in similar neighborhoods or private housing in low income neighborhoods, on parents and children's mental health. Families were selected from census tracts whose poverty rate exceeded $40 \%$. The experimental group was provided Section 8 housing vouchers and special 
assistance to move only to low poverty neighborhoods (poverty rates below 10\%). The primary motivation for the experimental group to participate in the program and to move to a higher income neighborhood was the strong prevalence of neighborhood crime and violence within the family unit. The control group also received Section 8 housing but remained in a neighborhood characterized by high poverty. According to the authors, who conducted a follow-up of the New York City group, the experimental parents and children exhibited statistically significant improvements in their overall well-being and mental health according to standardized measures. In comparison to the control group who were also provided Section 8 housing vouchers but remained in high poverty neighborhoods, the experimental group exhibited an improvement in overall mental health within both the parental and child populations. Parents were assessed according to presence of depressive, distress or anxiety.

Children were evaluated according to a Behavioral Problems Index, which assessed, anxiety/depressive disorders, dependency, a as well as anti-social characteristics. Experimental families' neighborhoods were characterized by a significantly higher household income, fewer low income residents. After a three year followup, experimental parents were found to exhibit a significant decrease in distress symptoms (20\%) as compared to the control group. Children who were in the experimental group were similarly less likely to exhibit anxious/depressive problems as compared to children in the control group.

Program effects were most significant for children ages 8 to 13 years. Among the male youth population, moving to private housing in low poverty neighborhoods resulted in a $25 \%$ reduction in depressive and anxietydriven problems by $25 \%$ within a 3 year period. Headstrong problems within the child experimental population similarly declined as compared to their peers in low income neighborhoods. Perhaps most significantly, the MTO site evaluations conclusively proved a reduction in male youth's arrests for violent crime and improvements in the child's overall health for incidents requiring medical intervention finally, the study implicates the inter-relationship of a family's neighborhood residence and socioeconomic differences in overall well-being and health, indicating a family's movement out of a low income neighborhood into a more high income neighborhood had positive mental health outcomes for both the parents and the children. This could also be attributable to the fact that higher income neighborhoods provide better health and social resources such as quality health services, recreational and park resources, schools and better housing. A study by Lawrence Katz et. al. (2000) of the Boston Move to Opportunity project found significant improvement in the overall mental health of parents who moved from low income to more economically stable neighborhoods. As in the New York City study (described later) families in the experimental group who moved to more affluent neighborhoods in Boston reported fewer anxiety and depressive symptoms implicit in increased feelings of safety and a decrease in exposure to neighborhood violence.

Adolescent children in the experimental group (as compared to adolescents in the control group who remained in low income neighborhood) exhibited a significant reduction in juvenile delinquent behaviors, including those leading to arrests. Experimental MTO families who moved from high- to low poverty neighborhoods were less likely to have children who were involved in criminal activities (i.e. violent crime). Neighborhood variables which were reported in the study ascribed the reduction in juvenile arrests within the experimental group to more frequent positive social interactions with peers, reduced negative stigmas associated with delinquent behaviors, as well as positive interactions with adults in the new neighborhood. In addition, higher quality community resources were associated in alleviating negative externalizing behaviors and promoting positive adolescent developmental results.

Poor adolescent mental health outcomes in low income neighborhoods may be directly related to chronic exposure to violence as well as difficulty concentrating due to sleep disturbances, images of traumatic events, as well as aggressive behavior due to imitation of behaviors by peers or self-protection. Socially and economically disadvantaged children and adults are similarly at risk for poor health outcomes. Pregnant and parenting mothers who are living in low income communities may have less access to adequate health care 
facilities, and may be at higher risk of complications during pregnancy. Pre-natal and post-partum medical complications have also been associated with poor child developmental outcomes.

\section{Policy Implications}

Low income children 0-5 years of age are particularly vulnerable during their infant and pre-school years to negative mental health and physical health outcomes in situations when a families is experiencing persistent poverty. The 1996 federal Welfare reform Law (POWRA), established a five year time limit for persons to receive Temporary Assistance for Needy Families (TANF) as well as cash assistance. In addition, states have wide discretion in lowering these time limits. Thus, the time limit cut-off for these programs can have significant detrimental effects on families and children, extending the length families must endure hardship.

Fewer family resources and prolonged exposure to persistent poverty can exacerbate parental conflict and result in dysfunctional parental strategies. In addition, states have varied somewhat in implementing the 1996 PWORA law in terms of restrictions and eligibility, perhaps undermining the family's efforts to achieve improved economic circumstances. Policies which are designed to alleviate persistent poverty should be focused upon a child's early years, rather than later, since these children are particularly vulnerable to the most detrimental effects of poverty in terms of negative mental health outcomes and later childhood development. Head Start services, particularly Early Head start programs with their complement of supportive services, should be fully supported.

The recent housing studies in New York City and Boston suggest strong evidence that moving to more stabilized neighborhoods has a long-lasting beneficial impact upon a family's overall mental health. Prolonged exposure to violence, crime and other safety-related concerns should inform decision-making at the state and federal level. Federal housing policy should therefore expand and support local housing authority initiatives to allow low income families to move to better neighborhoods. Housing policy should also address children's exposure to lead in low income communities. Lead exposure has also been associated with medical complications and adverse health outcomes.

Anti-poverty strategies in the United States have traditionally been applied indirectly, predicated upon a long standing tradition that the individual is ultimately responsible for his/her economic circumstances and should not be dependent upon direct intervention from the federal, state, or local government. This philosophy reached an apex in the 1996 PWORA Act which established clear time limits for federal cash assistance. However, educational and other programs such as Head Start, WIC and TANF can only minimally alleviate the economic hardships faced by families and are not a solution for families who have reached a tipping point. Ultimately, federal welfare policy should promote mental health and positive child developmental outcomes by improving their overall financial situation of families through workforce and expanded educational opportunities.

Programs such as the Workforce Investment Act's Dislocated Workers Program have a very short window of time between initial layoff and enrollment in the program. Many low income families who would benefit from the training and job placement components within this program may be unaware of the strict time limits in which they can enroll, before they are deemed ineligible. Finally, health disparities across the economic spectrum need to be addressed in a coordinated and non-discriminatory manner, ensuring quality health care access irrespective of a family/individuals financial situation. Federal /State agencies responsible for implementation of the Affordable Care Act should ensure that the Insurance Exchanges under the ACA are located in low socio-economic areas to ensure universal and even access. This is critical for parenting and pregnant low income mothers who without quality health care access, may undermine the health care and developmental outcomes of their child.

Higher rates of prenatal and post-partum complications, reduced access to resources which moderate the effects of prenatal complications, increased exposure to lead, and decreased access to cognitive stimulation play a role 
in the reduced cognitive functioning of children in lower income families. Inconsistent parenting, and increased exposure to negative life events associated with lower economic standing also plays a predictive role in a child's later development.

In short, federal and state policy must address the impact of time limited assistance and its impact on the psychosocial development of the child, as well as the overall stability within the family unit. This will ultimately lead to the improved functioning of families, and a more productive society, while ensuring the dignity of all families.

\section{References}

Augustyn et. al 1995 and Groves, Hampton et. al Interpersonal Violence in the African-American CommunityEvidence Based Prevention and Treatment Practices, Issues in Children's and Families Lives, April, 2010.

Barnett, M. (2008). Economic Disadvantage in Complex Family Systems: Expansion of Family Stress Models. Clinical Child and Family Psychology Review, 11(3), 145-161.

Benner, AD, Kim SY: Understanding Chinese American Adolescents Developmental Outcomes: Insights from the Family Stress Model;

Brooks-Gunn et. Al. Do Neighborhoods Influence Child and Adolescent Development, 1993, American Journal of Sociology

Ceballo, R., \& McLoyd, V. (2002). Social Support and Parenting in Poor, Dangerous Neighborhoods. Child Development, 73(4)

Duncan, G.: Families and Neighbors as the Source of Disadvantage in the schooling decisions of White and Black Adolescents, 1994, American Journal of Education

Economic Deprivation and Early Childhood Development, 1994, Child Development Duncan, G., Brooks-Gunn, J., \& Klebanov, P. (1994).

Hanson, T.: Economic Resources, parental practices, and Children's well-being, '1997, Russell Sage Foundation Herd, P. Goesling B. and House: Socioeconomic Position and Health, The differential effects of Education vs. income on the onset versus progression of health problems: Journal of Health and Social Behavior, 2007,

Katz, L., Kling, J., \& Liebman, J. (2001). Moving to Opportunity in Boston: Early Results of a Randomized Mobility Experiment. The Quarterly Journal of Economics, 116(2), 607-654.

Korenman, S. (1995). Long-term poverty and child development in the United States: Results from the NLSY. Children and Youth Services Review, 17(1), 127-155.

Kotlowitz, A.: There Are No Children Here, 1991

Leventhal, T., Fauth, R., \& Brooks-Gunn, J. (2005). Neighborhood Poverty and Public Policy: A 5-Year Follow-Up of Children's Educational Outcomes in the New York City Moving to Opportunity Demonstration. Developmental Psychology, 41(6)

Linver, MR and Brooks-Gunn, Family Processes as pathways from income to young children's development, 2002 Developmental Psychology; Young, et. al:

McLeod, J. et. al. : Poverty, Parenting, and children's mental health, 1993, American Sociological Review; McLoyd et. al. : Unemployment and work interruption among African-American Mothers, Effects on Parenting, 1994,Child Development

McLoyd, V.C., Ceballo, R. et. al. The Effects of Poverty on Children's Socio-Emotional Development, Handbook of Child and Adolescent Psychiatry, 1996

McLoyd, Vonnie: Socioeconomic Disadvantage and Child Development, February 1998, American Psychologist

Moving to Opportunity: an Experimental Study of Neighborhood Effects on Mental Health. American Journal of Public Health, 93(9), 1576

Parke RD et. al: Economic Stress, parenting, and child adjustment in Mexican American and European American Families, 2004, Child Development

Schofield, In Press 
Simons, L., Wickrama, K., Lee, T., Landers-Potts, M., Cutrona, C., \& Conger, R. (2016). Testing Family Stress and Family Investment Explanations for Conduct Problems Among African American Adolescents. Journal of Marriage and Family, 78(2), 498-515.

The Neighborhood Context of Adolescent Mental Health, 1996 Journal of Health and Social Behavior

Wilcox, W. (2008). Alone Together: How Marriage in America Is Changing - by Paul R. Amato, Alan Booth, David R. Johnson, and Stacey J. Rogers. Journal of Marriage and Family, 70(1),

Woodstock Institute, Chicago: Fact Sheet: Unequal Opportunity Disparate Mortgage Origination Patterns for Women in the Chicago Area, March, 2013.

2011-2015 American Community Survey (ACS) 1 and 5 Year Estimates: U.S. Census Bureau 